\title{
SPACE SIMULATION OF THE CHINA-BRAZIL EARTH RESOURCES SATELLITE - CBERS
}

\author{
E. C. Garcia ${ }^{a}$, \\ M. B. dos Santos ${ }^{b *}$, \\ J. S. de Almeida ${ }^{c *}$, \\ and D. L. Panissi ${ }^{\mathrm{d} *}$

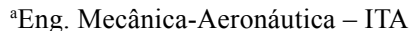 \\ 12228-900 - São José dos Campos - SP Brasil \\ ezio@mec.ita.br \\ bbueno@lit.inpe.br \\ cjsergio@lit.inpe.br \\ ${ }^{\mathrm{d}}$ panissio@lit.inpe.br \\ *Laboratório de Integração e Testes - INPE \\ Avenida dos Astronautas, 1758 \\ 12227-010 - São José dos Campos - SP \\ Brasil \\ ABSTRACT \\ Space Simulation Tests are performed in spacecraft in order to verify equipment proper \\ operation under thermal vacuum conditioning and to verify the correct workmanship in \\ the assembling of the flight spacecraft as a whole. This paper presents the space simulation \\ (thermal vacuum test) developed in the China Brazil Earth Resources Satellite, Flight \\ Model no. 2, that took place at the Integration and Tests Laboratory - LIT, INPE. Measuring \\ approximately $1.8 \times 2.0 \times 2.2 \mathrm{~m}$, weighting $1,500 \mathrm{~kg}$ and carrying three cameras as the \\ main payload, this spacecraft is scheduled to be launched in China. The spacecraft was \\ installed in the $3 \times 3 \mathrm{~m}$ space simulation chamber and the tests run 24 hours a day completing \\ a total of 350 hours. Using the technique of skin-heaters complemented by the thermal \\ vacuum chamber thermally conditioned shrouds and cold plates, dedicated heat inputs \\ and heat sink where applied at the spacecraft surfaces in order to obtain the required high \\ and low acceptance values of temperature and, subsequently, simulating the operational \\ conditions for the necessary electronic subsystems functioning tests of the spacecraft. \\ This test campaign included teams from both China and Brazil, summing a total of 67 \\ people directly involved. \\ Keywords: Space Simulation, Satellite, Thermal Control, CBERS, Thermal Vacuum \\ Fax (55) 12 3941-1884
}

\section{INTRODUCTION}

This paper details the approach adopted and applied in the Space Simulation (SS) campaign of the China Brazil Earth Resources Satellite, Flight Model \#2, (CBERS-FM2), successfully performed at the Integration and Tests Laboratory - LIT, National Institute for Space Research - INPE, in São José dos Campos, SP, from September $7^{\text {th }}$ to $28^{\text {th }}, 2001$. Measuring approximately $1.8 \times 2.0 \times$ $2.2 \mathrm{~m}$, weighting $1,500 \mathrm{~kg}$ and carrying three cameras as the main payload, this spacecraft $(\mathrm{S} / \mathrm{C})$ is scheduled to be launched in China and it will be orbiting the Earth at $778 \mathrm{~km}$ as part of its remote sensing mission profile as represented by Fig. 1.

Satellites are subjected to extensive ground thermal testing to verify its thermal design and ensure successful operational use in flight. The MIL-STD-1540B (1982) standardizes the test requirements and establishes a uniform set of definitions, environmental criteria, and test methods for military space vehicles, subsystems and components.

The test environment was built to simulate the various environmental stresses to which the satellite was designed. The thermal stresses adopted in the design were related to equipment operation, internal heating, eclipse conditions, space-vehicle orientation, environmental heating (including solar, earthshine infrared and albedo radiation), ascent heating, and degradation of thermal surfaces during the mission lifetime. These stress conditions are used in the analytical modeling in order to predict, over the operational lifetime of the spacecraft, the worst-case hot and cold temperatures for the component, subsystem and for the satellite. From these results, acceptance and qualification temperatures are derived (Gilmore, 1994).

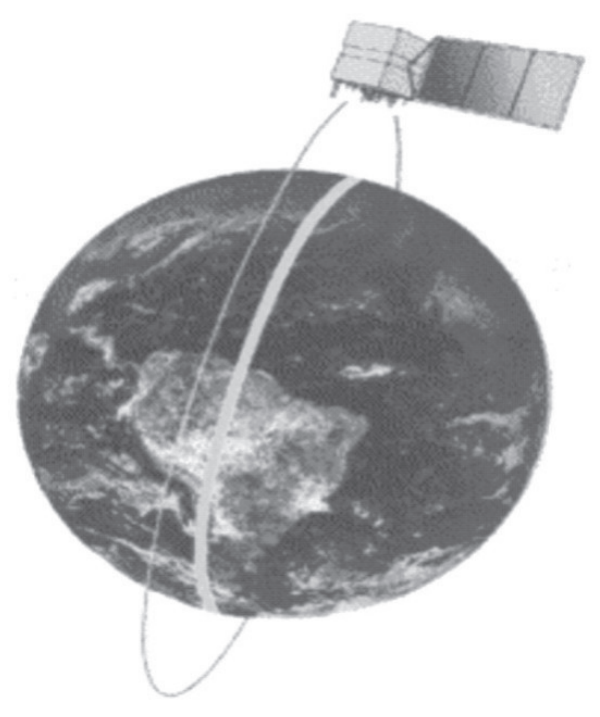

Figure 1. CBERS-FM2 Satellite Mission. 


\section{TECNOLOGIA/TECHNOLOGY}

The primary purpose of the space simulation (or thermal vacuum test) is to verify the functional performance of the satellite. Without the convective heat transfer environment, the temperature and stresses closely simulate the on-flight conditions. Following the requirements from MIL-STD1540B (1982), a minimum of four cycles are required at the acceptance level, where each cycle is then composed by both the maximum and minimum predicted temperatures.

Exploring the capabilities of the $3 \mathrm{~m} \times 3 \mathrm{~m}$ Thermal Vacuum (T/V) Chamber from LITINPE in terms of appropriately selecting and adjusting its cold shroud temperatures (heat sink) and also some low cost heat input/sink techniques, the CBERS-FM2 spacecraft was adequately disjoined at its service and payload model interface in such a way that each section could physically fit inside the T/V Chamber one at a time. Assuring all the necessary functional and test cabling interconnection between the two models through the chamber walls for the proper spacecraft electrical operations as an integrated system, specific thermal test techniques were applied in order to obtain the required hot and cold acceptance levels of temperature at the spacecraft subsystems and structural surfaces, as a consequence of the simulated thermal conditioning from the distinct orbital configurations. These thermal simulation techniques consisted of a combination of skinheaters, the thermal vacuum chamber main shrouds (operating as heat sinks) and dedicated Liquid Nitrogen (LN2) cold plate, effectively leading to reliable and very satisfactory testing methodology results.

Taking more than 350 hours and having 67 people directly involved, including teams from both INPE and CAST (Chinese Academy of Space Technology), this test can be considered as a very important accomplishment in terms of distinct technique of spacecraft testing and also in terms of the satisfactory working relationship between two quite different cultures as the Brazilian and the Chinese.

In this paper the satellite subsystems will be referred by their codes as stated in the CBERS program. Weiqun and Carleial (1992) describe the correlation of each equipment code.

\section{CBERS-FM2 SPACE SIMULATION REQUIREMENTS}

The execution of the CBERS-FM2 space simulation tests complied with the maximum and minimum temperatures defined for acceptance level, as described in the CBERS Environmental Specification (Zhixu et al., 1996). This document also presents the main operating temperatures for equipment in acceptance level. The T/V Chamber pressure was required to be less than $1.33 \times 10^{-3} \mathrm{~Pa}$.

\section{SIMULATION OUTLINE}

Basically, the CBERS FM2 Space Simulation consisted in cycling the satellite equipment to two (hot and cold) temperature soaks in a vacuum environment, while functional tests were performed in each soak. According to Zhixu et al. (1996), the satellite had to remain at each temperature soak for 8 hours. The time duration at the temperature soak had to be sufficient to test orbital operational conditions and all the equipment functional modes. Four cycles were performed. This procedure would allow the possibility of equipment failures due to fabrication or handling procedures to be identified. In Fig. 2, one cycle of the SS is illustrated.

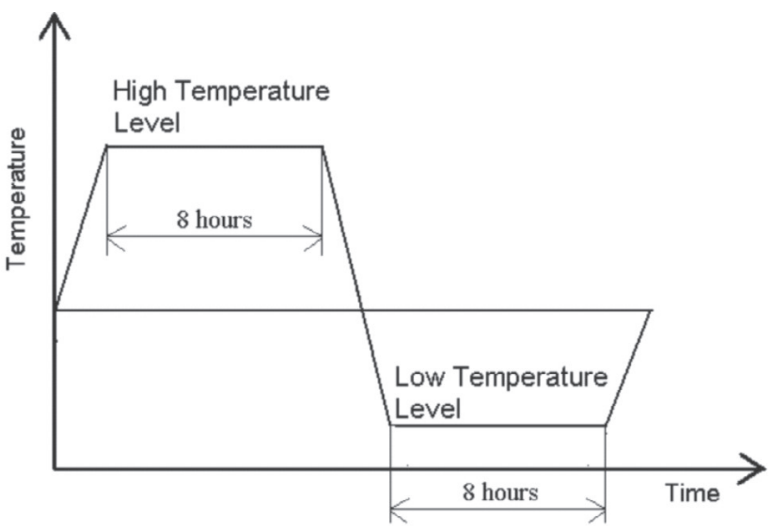

Figure 2. Space Simulation Temperature Cycle.

In the SS of CBERS-FM2, the satellite was submitted to functional tests in each temperature soak, while in transition from one temperature soak to the next one, it was kept most of the time in standby mode.

Due to the limited size of LIT's thermal vacuum chamber, the SS of CBERS-FM2 was conducted in two phases. The Service Module (SM) had to be separated from the Payload Module (PM), 
so that each module could be put inside of the T/V chamber and tested one at a time.

The following test philosophy was adopted:

- Test hot soaks: impose $+5 \sim+10^{\circ} \mathrm{C}$ above the predicted hot case flight temperatures in each satellite module to obtain the simulation predicted temperatures.

- Test cold soaks: impose $-5 \sim-10^{\circ} \mathrm{C}$ below of the predicted cold case flight temperatures in each satellite module to obtain the simulation predicted temperatures.

- Assure that the temperatures of the modules remain between the simulation predicted temperatures and the acceptance levels.

- First the Service Module was tested, followed by the Payload Module.

- The Solar Array Generator (solar panel) was not integrated in the spacecraft during the SS. The BAPTA motor was checked for its correct operation.

- The majority of the antennas were removed from SM and PM. The SS was performed using RF cables only.

The SS electrical cabling (high and low frequency) was designed and built by the LIT team. Garcia (2001) presents the cabling configurations in the thermal vacuum procedures for SM and PM simulations. Garcia (2001) also presents the Predicted Flight Temperatures for Flight and for Space Simulation of CBERS-FM2, for the hot and cold cases. In the same way, Garcia (2001) also shows a correlation between nodes from the mathematical model and equipment codes.

\section{SERVICE MODULE OF CBERS-FM2 SATELLITE}

This module was tested to SS in Sept., 0714, 2001. Figure 3 presents the SM installation in the $3 \mathrm{~m} \times 3 \mathrm{~m}$ T/V Chamber.

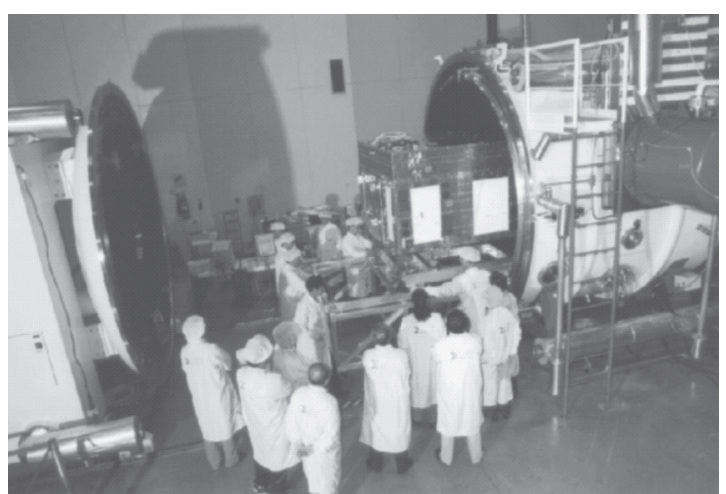

Figure 3. SM installation in the $3 \mathrm{~m} \times 3 \mathrm{~m}$ T/V Chamber.
For the cold and hot soaks, the shroud temperature (heat sink) of the $\mathrm{T} / \mathrm{V}$ Chamber was set to $-25^{\circ} \mathrm{C}$ and to $+10^{\circ} \mathrm{C}$, respectively.

To reduce the time necessary for the transition between soaks, the shroud temperature was set to $-50^{\circ} \mathrm{C}$ and to $+25^{\circ} \mathrm{C}$ for the hot-cold and cold-hot soak changes, respectively. When the convergence criteria (Fu and Garcia, 2000) had been reached, the shroud temperature was again set to $-25^{\circ} \mathrm{C}$ and to $+10^{\circ} \mathrm{C}$ for the cold and hot soaks.

The side panel Multi Layer Insulations (MLI) were removed to increase the thermal coupling between the SM and T/V chamber shroud. Kapton films were adhered to the side panels, external surfaces (except white paints and Optical Surface Reflector - OSR). Adhesive transfer tapes (3M - 467) were used to adhere Kapton films on the side panels. After the test finished it was not necessary to remove these Kapton films, but the MLI's were applied again over these films, following the design. Also, where necessary, the skin-heaters were adhered to the Kapton film, assuring an electrical insulation between the heaters and the SM. After the test, the skin-heaters were removed from the SM.

To increase the temperatures of some equipment and ensure acceptance level temperature, skin-heaters were bonded to the external surface of the wall panels. A total power of $\sim 500$ watts was distributed in 11 independent loops for the SM compartments. The skin-heaters, power supply setup, heater positions, and installation procedure are described in more detail in the FM2 thermal vacuum test procedure (Garcia, 2001).

The whole external surface of the $\mathrm{SM}+\mathrm{Z}$ face was covered with a $2 \mathrm{~mm}$ aluminum plate with MLI made by 10 layers. The middle panels were assembled in the SM. So, the $2 \mathrm{~mm}$ aluminum plate with MLI was placed on top of the middle panels in the $\mathrm{X}-\mathrm{Y}$ plane. Then, the $\mathrm{SM}+\mathrm{Z}$ face was thermally isolated from the T/V chamber shroud. Skin-heaters were adhered to the $2 \mathrm{~mm}$ aluminum plate to simulate the thermal load coming from the PM.

The interface between the SM and the thermal vacuum chamber support had to be heat conduction uncoupled. The technique employed was placing skin-heaters in the interface. Controllers operate with these skin-heaters in order to guarantee a low temperature difference between the SM and T/V chamber support. 


\section{TECNOLOGIA/TECHNOLOGY}

A cold plate filled with liquid nitrogen was positioned next to the Battery panel. So, the Battery panel was thermally coupled only with a cryogenic surface (temperature around $-180^{\circ} \mathrm{C}$ ). This LN2 plate had a 15 layers MLI on its external face and presented an emissivity higher than 0.8 on its internal surface. This setup is presented in Fig. 4.

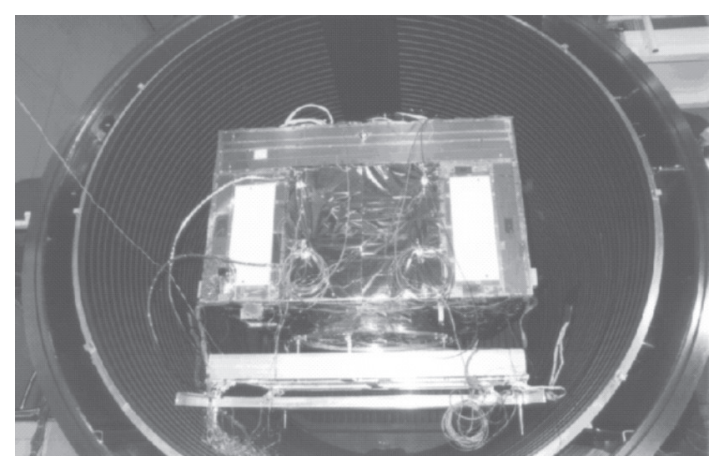

Figure 4. This picture presents the support, the Liquid Nitrogen Plate positioned on Battery Panel (at the center of the SM, silver color) and Thermal Vacuum Chamber.

The propulsion system was pressurized with nitrogen gas (GN2) (purity $>99.995 \%$ ) at 1.7 MPa.

The CBERS-FM2 Batteries were used for the SS (not an Engineering Model Product).

The equipment of SM was monitored by 33 thermistors plus 21 thermocouples (a total of 54). Also, 28 additional thermocouples were used to verify the temperature of the SM panels, the interface between SM and support, and the LN2 cold plate.

The beginning of both hot and cold temperature soaks for the SM was considered to had been reached when all equipment matched the predicted temperatures (Garcia, 2001) within a margin of $\pm 2.5^{\circ} \mathrm{C}$.

The time to perform one cycle for the SM $\mathrm{T} / \mathrm{V}$ test was 40 hours. Thus, the SM T/V test duration was about 7 days.

Figures 5 and 6 present in sequence the temperature profiles (cycles) developed in some SM compartments.
E. C. Garcia et al. Space Simulation of The...

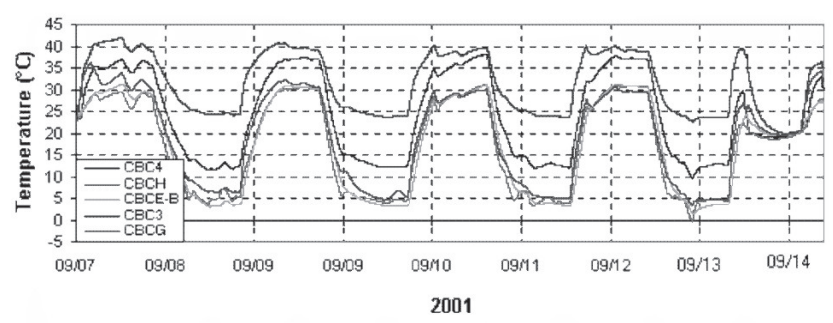

Figure 5. Temperature profile in the equipment $\mathrm{CBC} 4, \mathrm{CBCH}, \mathrm{CBCE}-\mathrm{B}, \mathrm{CBC} 3$ and $\mathrm{CBCG}$, which are located inside of the SM2 compartment.

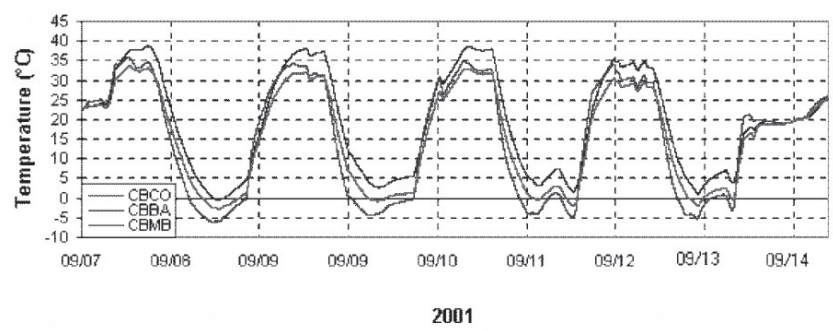

Figure 6. Temperature Profiles in the propulsion system (equip. CBCO, CBBA, CBMB) which are located inside the SM9 compartment.

\section{Test anomalies}

Two main anomalies were identified, as following:

- The white paint of the sidewall panel $+X$ (heat rejection area) was unbounded during the SS. It was verified just after opening the $\mathrm{T} / \mathrm{V}$ chamber door. Figure 7 presents a picture of this panel with part of the paint that was unbounded inside of the $\mathrm{T} / \mathrm{V}$ Chamber.

- The RIGA equipment (Chinese) and SEM presented mal-functioning during the SS. The CAST team had the responsibility of identifying the problems and to present solutions.

\section{PAYLOAD MODULE TEST OF THE CBERS-FM2 SATELLITE}

The Payload Module (PM) Test was performed from September 20 - 28, 2001.

For the PM cold and hot soaks, the shroud temperature was set to $-15^{\circ} \mathrm{C}$ and to $+20^{\circ} \mathrm{C}$, respectively. Also, to decrease the time necessary for the transition between soaks, the shroud temperature was set to $-20^{\circ} \mathrm{C}$ and to $+35^{\circ} \mathrm{C}$ for the hot-cold and cold-hot soak changes, respectively. When the convergence criteria was obtained, the shroud temperature was again set to $-15^{\circ} \mathrm{C}$ and to 
$+20^{\circ} \mathrm{C}$ for the cold and hot soaks, respectively. Also, the time to perform one cycle for the PM space simulation was 40 hours. Thus, the SS duration for the PM test was 7 days.

Figure 8 presents the PM installation inside the $3 \mathrm{~m} \times 3 \mathrm{~m}$ T/V Chamber.

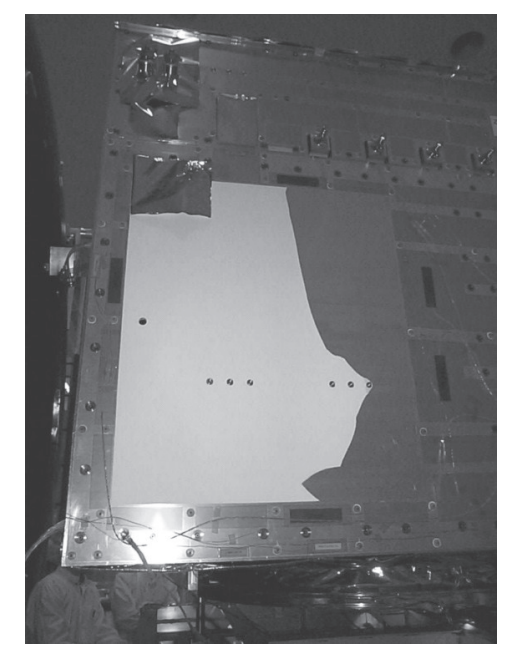

Figure 7. Heat rejection area (white paint) unbounded off the $+X$ sidewall SM panel.
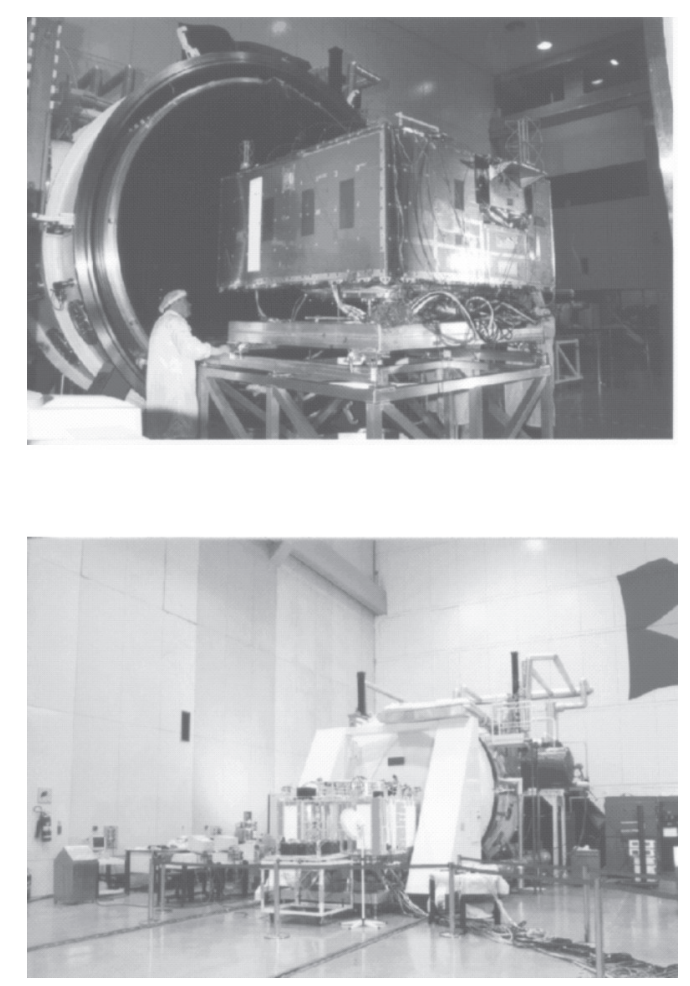

Figure 8. Top: PM installation in the $3 \mathrm{~m} \times 3 \mathrm{~m}$ T/V hamber. Bottom: view of the complete setup, including the SM positioned outside the T/V.

The PM roof panel was covered with MLI, as designed for flight. All side panel MLI's were removed to increase the thermal coupling between the PM and T/V chamber shroud. Again, Kapton films were adhered to the side panels, external surfaces (except for white paints and OSR surfaces). Also, to increase the temperatures of some equipment and ensure acceptance level temperature, skin-heaters were bonded to the external surface of the wall panels. These can be seen in Figs. 8 and 9. A total power of 400 watts was distributed in 10 independent loops for the PM compartments. The power in each compartment was uniformly distributed on its wall panel. The skin-heaters, power supply setup, heater positions and installation procedure are described in more detail in the FM2 Thermal Vacuum Test procedure (Garcia, 2001).

The interface between the PM and the thermal vacuum chamber support had to be heat conduction uncoupled as well. The technique employed was placing skin-heaters at the interface. Controllers operated these skin-heaters to guarantee a minimum temperature difference between the PM and $\mathrm{T} / \mathrm{V}$ chamber support.

The flight CBERS-FM2 Infrared Multi Spectral Scanner (IRMSS) was replaced by the engineering model (EM) camera in the following configuration:

- The scanner mainframe was the EM product;

- The amplifier, encoder and radiative cooler controller were CBERS-FM2 products;

- The CBERS-FM2 Flight CCD camera was used for the $\mathrm{T} / \mathrm{V}$ test.

A $\mathrm{LN}_{2}$ Cold Plate was positioned near the PM bottom section to remove possible contamination from the satellite. This plate operated as a trap and a significant quantity of contamination was removed from PM. Also, twelve witness plates were installed on $\mathrm{T} / \mathrm{V}$ Chamber walls and PM surfaces to detect any contamination problems. As a result, high levels of esters and methyl-silicone contamination were detected on a sensor installed next to the $\mathrm{T} / \mathrm{V}$ chamber decontamination plate. After the test, the contamination, which had been moved from the satellite to LN2 cold plate, had dropped on T/V chamber shroud. Also, wipe tests (collect of material after the test) were raised from $\mathrm{T} / \mathrm{V}$ chamber and PM surfaces. In these situations high levels of esters and methyl-silicone were detected at the center of the shroud and next to LN2 plate. 


\section{TECNOLOGIA/TECHNOLOGY}

In addition, high levels of methyl-phenyl-silicone were detected on IR/DT Converter Equipment surface and on CCD Camera (internal surface).

The PM equipment was monitored by 30 thermistors plus 31 thermocouples (a total of 61). Also, additional 36 thermocouples were used to verify the temperature of the PM panels, interface between PM and support, and LN2 plate. The start point of both hot and cold temperature soaks for the PM was considered to had been reached when all equipment had matched the predicted temperatures (Garcia, 2001) within a margin of $\pm 2.5^{\circ} \mathrm{C}$. Figures 10 and 11 present the temperature profiles (cycles) developed in some of the PM compartments.

\section{Test anomalies}

An anomaly was verified during PM space simulation: the equipment RTU-4 presented a malfunction behavior. INPE's team had the responsibility of identifying the problem and to present solutions.

\section{PERSONNEL DIRECTLY INVOLVED}

The teams and quantity of people involved during the SS of SM and PM is related as following:

- Thermal Vacuum (LIT): 12

- $\mathrm{S} / \mathrm{C}$ Integration \& Electrical (LIT): 06

- T/V Data Acquisition (LIT): 03

- Lab. Maintenance (LIT): 04

- INPE Thermal Design: 01

- INPE Product Assurance: 01

- CAST: 40

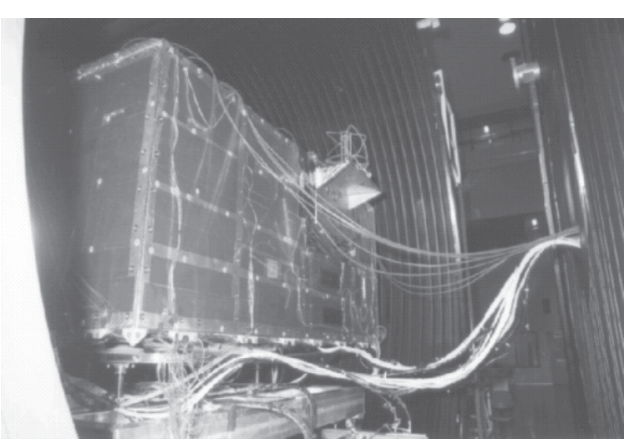

Figure 9. PM installed inside the T/V Chamber. View of the electrical interface cabling to SM, which was positioned outside the T/V Chamber.
E. C. Garcia et al. Space Simulation of The...

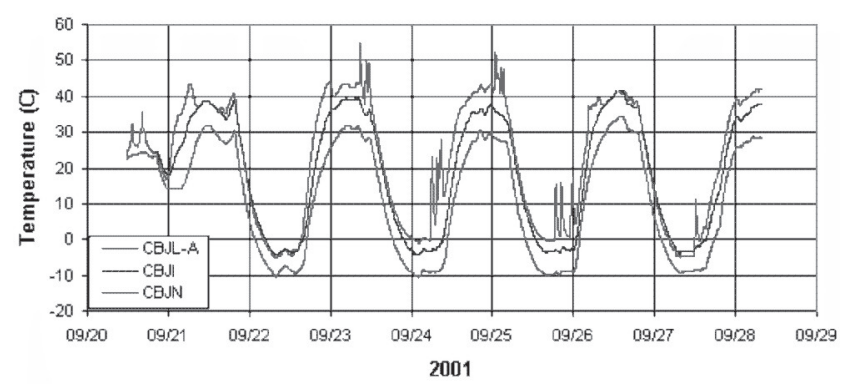

Figure 10. Temperature profiles developed in the equipment CBJL-A, CBJI and CBJN. (PM2 compartment).

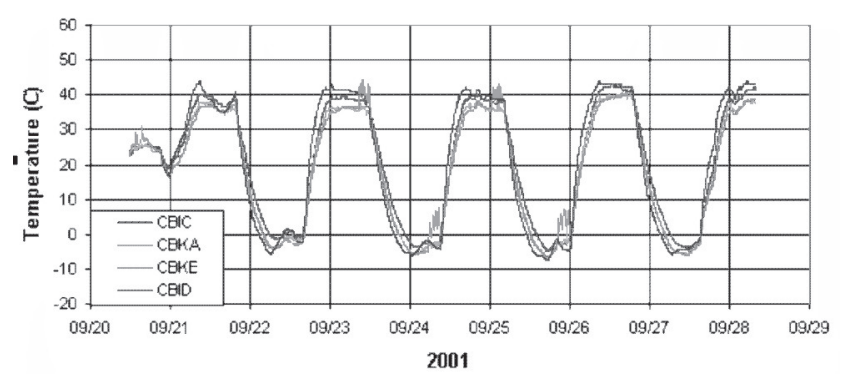

Figure 11. Temperature profiles developed in the equipment CBIC, CBKA, CBKE and CBID. (PM5 compartment).

\section{CONCLUSIONS}

The test results show that the main objectives of achieving high vacuum condition and equipment temperature between the minimum (for the hot cases) and maximum (for the cold cases) of the predicted acceptance level temperatures were successfully satisfied. Tables 1 and 2 present the quantity of equipment for SM and PM, respectively, that had their temperature values inside the temperature convergence range (in terms of percentages).

In 1998, the first satellite from the Brazilian-Chinese cooperation (CBERS-FM1) was tested in Beijing. The FM1 test technique used in Beijing was to keep the $\mathrm{T} / \mathrm{V}$ chamber shroud at LN2 temperature $\left(-196^{\circ} \mathrm{C}\right)$. The thermal loads were imposed by skin-heaters plus the installation of electrical strips (operating in the infrared radiation spectrum), near some areas of the satellite, as CCD, IRMSS and WFI cameras. Also, the satellite was not separated in two modules. The PM was mechanically coupled with the SM and both were put inside the $12 \mathrm{~m} \times 7 \mathrm{~m}$ Chinese T/V Chamber. So, the Brazilian technique used for the FM2 testing was pretty different from the Chinese. Tables 3 and 


\section{TECNOLOGIA/TECHNOLOGY}

4 present an analysis of the results obtained from the FM1 (fulfilled by Chinese technique) and the FM2 (fulfilled by Brazilian technique).

The main conclusions of the CBERSFM2 Space Simulation are:

- Thermal vacuum chamber run 350 hours with no problems (very smooth test);

lost;

- Data acquisition run fine, without data

- Skin-heaters technique proved to be reliable;

- Temperature convergence criteria well satisfied

- 67 people directly involved with good relationship and cooperation between Chinese and Brazilian teams;

- SS of FM2 (accomplished in Brazil) had better performance than FM1 satellite (accomplished in China);

- CBERS FM2 Space Simulation performed at LIT/INPE with complete success.

\section{ACNOWLEDGEMENTS}

The authors are thankfull to CNPq for the financial support.

Table 1. Quantity of SM equipment inside of the test convergence range.

\begin{tabular}{|c|c|c|}
\hline Cycle & Hot Case & Cold Case \\
\hline $1^{\text {st }} C y c l e$ & $96.3 \%$ & $81.5 \%$ \\
\hline $2^{\text {nd }} C y c l e$ & $92.6 \%$ & $90.7 \%$ \\
\hline $3^{\text {rd }} C y c l e$ & $90.7 \%$ & $81.1 \%$ \\
\hline $4^{\text {th }}$ Cycle & $96.0 \%$ & $88.0 \%$ \\
\hline Overall & $94.4 \%$ & $85.3 \%$ \\
\hline
\end{tabular}

Table 2. Quantity of PM equipment inside of the test convergence range.

\begin{tabular}{|c|c|c|}
\hline Cycle & Hot Case & Cold Case \\
\hline $1^{\text {st }} C y c l e$ & $89.0 \%$ & $94.6 \%$ \\
\hline $2^{\text {nd }} C y c l e$ & $92.9 \%$ & $85.7 \%$ \\
\hline $3^{\text {rd }} C y c l e$ & $81.9 \%$ & $89.0 \%$ \\
\hline $4^{\text {th }}$ Cycle & $87.5 \%$ & $85.8 \%$ \\
\hline Overall & $87.8 \%$ & $88.8 \%$ \\
\hline
\end{tabular}

Table 3. FM1 versus FM2 Convergence Performance Analysis during Hot Cases.

\begin{tabular}{|c|c|c|}
\hline Hot Case & FM1 & FM2 \\
\hline $1^{\text {st }}$ Cycle & $93.0 \%$ & $92.6 \%$ \\
\hline $2^{\text {nd }}$ Cycle & $82.5 \%$ & $92.7 \%$ \\
\hline $3^{\text {rd }}$ Cycle & $81.0 \%$ & $86.3 \%$ \\
\hline $4^{\text {th }}$ Cycle & $86.0 \%$ & $91.7 \%$ \\
\hline Overall & $85.6 \%$ & $90.9 \%$ \\
\hline
\end{tabular}

Table 4. FM1 versus FM2 Convergence Performance Analysis during Cold Cases.

\begin{tabular}{|c|c|c|}
\hline Cold Case & FM1 & FM2 \\
\hline $1^{\text {st }}$ Cycle & $74.0 \%$ & $88.0 \%$ \\
\hline $2^{\text {nd }}$ Cycle & $90.0 \%$ & $88.2 \%$ \\
\hline $3^{\text {rd }}$ Cycle & ND & $85.0 \%$ \\
\hline $4^{\text {th }}$ Cycle & ND & $86.9 \%$ \\
\hline Overall & $82.0 \%$ & $87.0 \%$ \\
\hline
\end{tabular}

\section{REFERENCES}

Fu, P. Z. and Garcia, E. C, 2000, Specification for CBERS FM2 Thermal Vacuum Test, Private Communication, INPE, doc. c-hds0022, São José dos Campos, Brazil, 39p.

Garcia, E. C., 2001, SM Thermo Vacuum Test Thermal Control Procedure, Private Communication, INPE, doc. lit01-cbers-tp-027, São José dos Campos, 34p.

Garcia, E. C., 2001, PM Thermo Vacuum Test Thermal Control Procedure, Private Communication, INPE, doc. lit01-cbers-tp-028, São José dos Campos, 31p.

Gilmore, D. G., 1994, Satellite Thermal Control Handbook, The Aerospace Corporation Press, chapter ix, El Segundo, California, pp. 9.39.35 .

MIL-STD-1540B (USAF), 1982, Test Requirements for Space Vehicles, Military Standard.

Weiqun, S. and Carleial, A. B., 1992, CBERS Satellite Product Matrix, Private Communication, CAST-INPE, doc. cb-mng-010, São José dos Campos, 10p.

Zhixu, S., Wenming, Z., Bueno, L. A. R. and Stephany, S., 1996, Environmental Specification, Private Communication, INPE, doc. Cb-evs-001, São José dos Campos, 34p. 